Research Article

\title{
Study of hypoglycemic activity of Tinospora cordifolia in alloxan induced diabetic rabbits
}

\author{
Saleem B. Tamboli*, Sumit P. Sontakke, Rahul B. Parsode
}

Department of Pharmacology, Dr. Shankarrao Chavan Government Medical College, Nanded-431601, Maharashtra, India

Received: 25 June 2013

Accepted: 21 July 2013

*Correspondence to:

Dr. Saleem Basha Tamboli,

Email:

microbiopharma@rediffmail.com

(C) 2013 Tamboli SB et al. This is an open-access article distributed under the terms of the Creative Commons Attribution Non-Commercial License, which permits unrestricted non-commercial use, distribution, and reproduction in any medium, provided the original work is properly cited.

\begin{abstract}
Background: This study was designed to investigate the hypoglycemic effect of Tinospora Cordifolia in alloxan-induced diabetic rabbits.

Methods: Rabbits were divided into four experimental groups: Nondiabetic rabbits treated with normal saline, Non-diabetic rabbits treated with TCREt, Diabetic rabbits treated with Metformin, Diabetic rabbits treated with TCREt. Treatment with drugs was started on the 8th day of alloxan treatment (i.e. day 1) and was continued for 30 days. Statistical evaluation was done using student's ' $t$ ' test \& one way ANOVA followed by Tuckey`s post hoc test. ' $p$ ' value less than 0.05 was considered statistically significant.

Results: TCREt showed hypoglycemic action in alloxan induced diabetes rabbits. It did not produce hypoglycemia in non diabetic rabbits.

Conclusion: Hypoglycemic action of TCREt is comparable to that of standard oral hypoglycemic drug metformin.
\end{abstract}

Keywords: Tinospora Cordifolia, Diabetes, Metformin

\section{INTRODUCTION}

Once regarded as a single disease entity, diabetes mellitus is now seen as heterogeneous group of diseases characterized by a state of chronic hyperglycemia resulting from a diversity of etiologies, environmental and genetic factors acting jointly. The chronic hyperglycemia of diabetes is associated with long term damage, dysfunction and failure of various organs, especially the eyes, kidneys, nerves, heart and blood vessels. ${ }^{1}$

Six out of top ten countries with the highest rates are in south-East Asia region. India ranked first in the list of countries with the highest numbers of estimated cases of diabetes for 2000 and estimated to be same by $2030 .^{2}$

Hypertension is an extremely common co-morbid condition in diabetes, affecting $20-60 \%$ of patients with diabetes, depending on obesity, ethnicity and age. In type 2 diabetes, hypertension is often present as part of the metabolic syndrome including central obesity and dyslipidemia. ${ }^{3}$

The aqueous Tinospora cordifolia root extract (TCREt) has been used in treating diabetes in traditional medicine. Currently various parts of Tinospora cordifolia have shown several medicinal properties including hypoglycemic activity. Several animal and human models have demonstrated the hypoglycemic activity of TCREt .The present study is designed to compare the hypoglycemic activity of TCREt with standard oral hypoglycemic drug metformin.

\section{METHODS}

The present study was carried out in Department of Pharmacology at Dr S.C. Government Medical College, 
Nanded, Maharashtra, India after approval by Institutional Animal Ethics Committee. Handling and care of animals was according to CPCSEA guidelines. Care was taken during the animal study including food, water, shelter place (Housing), prevention of infection etc.

\section{Materials}

- Experimental animals used in the study: Healthy New Zealand rabbits.

- Disposable syringes \& needles, oral feeding (blunt curved) needle, mouth gag.

- Glucometer and strips. Lifescan: Johnson \& Johnson Co.

- Drugs:

1. Alloxan monohydrate obtained from Loba Chemie Pvt. Ltd., Mumbai, India.

2. Metformin obtained from Hoechst India Limited, Mumbai, India.

3. Tinospora Cordifolia hydrochloride obtained from Natural Remedies private Ltd, Bangalore.

4. Vehicle (Normal saline, distilled water).

\section{Experimental design}

It was a prospective, randomized, analytical, interventional, single blind study. New Zealand rabbits weighing between $1-1.5 \mathrm{~kg}$ were used for the study. For the experiment, the animals were weighed, numbered and randomly divided into four groups of 6 animals each.

\section{Induction of diabetes mellitus}

A single dose $(150 \mathrm{mg} / \mathrm{kg})$ of freshly prepared solution of Alloxan monohydrate 5\% (dissolved in normal saline) was administered intravenously in lateral marginal ear vein for induction of type 2 diabetes mellitus in the rabbits. Blood sample was collected from lateral marginal vein of ear. Blood glucose level estimated by glucose oxidase method using glucometer. Blood sample was taken on $1,3,7,14,21 \& 28$ day $^{4}$, by the demonstration of blood glucose in the range of $250-350 \mathrm{mg} / \mathrm{dl} .^{5}$

\section{Animal groups}

Rabbits were divided into four groups as below:

Group 1: Non-diabetic rabbits treated with normal saline Group 2: Non-diabetic rabbits treated with TCREt (50 $\mathrm{mg} / \mathrm{kg})^{6}$

Group 3: Diabetic rabbits treated with Metformin (120 $\mathrm{mg} / \mathrm{kg})^{7}$

Group 4: Diabetic rabbits treated with TCREt $(50 \mathrm{mg} / \mathrm{kg})$

\section{Statistical analysis}

The data was expressed as mean \pm standard deviation (SD) and Statistical evaluation was done using student's ' $t$ ' test \& one way ANOVA followed by Tuckey's post hoc test. 'p' value less than $0.05(\mathrm{P}<0.05)$ was considered statistically significant.

\section{RESULTS}

The drugs were administered orally to animals once daily for 30 days. Euglycemic as well as alloxan-induced diabetic animals were subjected for various treatments as mentioned earlier. Mean $( \pm$ SD) values of blood glucose levels in different Group of animals are shown in Table 1.

Table 1 shows variation in blood glucose levels from day 1 to day 28 in each group. Mean BGL in non diabetic control (NS) and non diabetic test (TCREt) varied between 169.8 to $182.4 \mathrm{mg} / \mathrm{dl}$ throughout the study period. In standard control group (DM + MET) there was significant reduction of BGL from day $1(293.5 \mathrm{mg} / \mathrm{dl})$ to day $28(136.5 \mathrm{mg} / \mathrm{dl})$. In test group, which received 50 $\mathrm{mg} / \mathrm{kg}$ body weight of root extract of Tinospora cordifolia, there was no significant reduction in BGL on day 1 and day 3, from day 7 there was gradual reduction of BGL from $265.9 \mathrm{mg} / \mathrm{dl}$ to $175 \mathrm{mg} / \mathrm{dl}$ on day 28 . When the two groups (test and standard) were compared between there day 1 and day 28 findings, the difference was found statistically significant.

Table 1: Mean $( \pm$ SD) values of blood glucose levels in different groups.

\begin{tabular}{|lllllll|}
\hline Groups & Day 1 & Day 3 & Day 7 & Day 14 & Day 21 & Day 28 \\
\hline ND+ NS & $180.0 \pm 8.1$ & $179.9 \pm 7.3$ & $182.4 \pm 8.1$ & $178.6 \pm 6.3$ & $180.5 \pm 7.8$ & $174.5 \pm 6.9$ \\
\hline ND+ TCREt & $177.4 \pm 10.3$ & $172.5 \pm 9.0$ & $170.9 \pm 9.8$ & $169.8 \pm 8.9$ & $176.1 \pm 7.9$ & $180.6 \pm 6.6$ \\
\hline D + MET & $293.5 \pm 49.5$ & $275 \pm 49.1$ & $252.4 \pm 43.2$ & $209 \pm 30.2$ & $173.3 \pm 23.3$ & $136.5 \pm 13.4^{*}$ \\
\hline D + TCREt & $296.6 \pm 37.4$ & $285.4 \pm 39.7$ & $265.9 \pm 32.7$ & $236.8 \pm 29.1$ & $208.1 \pm 26.3$ & $175 \pm 22.6^{*}$ \\
\hline
\end{tabular}

$* \mathrm{p}$ value $<0.005$ (when compared day 1 and day 28 findings) 


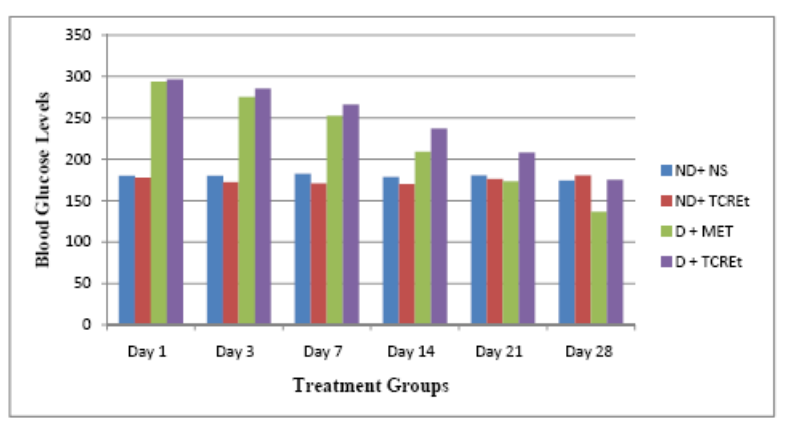

Figure 1: Mean ( \pm SD) values of blood glucose levels in different groups.

\section{DISCUSSION}

In this study the hypoglycemic action of Tinospora cordifolia in the form of aqueous root extract has been evaluated and its efficacy is compared with that of standard oral hypoglycemic drug metformin.

In our study, TCREt $(50 \mathrm{mg} / \mathrm{kg})$ decreased blood glucose level (BGL) from $296.6 \mathrm{mg} / \mathrm{dl}$ on day 1 to $175 \mathrm{mg} / \mathrm{dl}$ on day 28 (Table 1). The results show that Tinospora cordifolia in the form of aqueous root extract has definitive hypoglycemic activity. The present study is in accordance with the previous studies done by Stanley et al (2003) and Grover et al (2000) who reported the hypoglycemic action of TCREt. 8,9

In our study TCREt did not produce hypoglycemia in non diabetic test group (BGL-177.4 mg/dl on day 1 to 180.6 $\mathrm{mg} / \mathrm{dl}$ on day 28 (Table 1), which suggests that it might have antihyperglycemic activity in diabetic rabbits and no hypoglycemic activity in normal rabbits.

\section{CONCLUSION}

At the end of the study it can be concluded that aqueous root extract of Tinospora cordifolia has hypoglycemic effect in diabetic rabbits and it does not have hypoglycemic action in normal rabbits. The hypoglycemic activity is comparable to that of metformin in diabetic rabbits.

Thus refined TCREt could be used as an oral hypoglycemic agent in diabetes. However further extensive studies need to be done to confirm this activity in animal models as well as human trials.

Funding: None

Conflict of Interest: None declared

Ethical approval: The study was approved by the Institutional Animal Ethics Committee

\section{REFERENCES}

1. Park K. Textbook of preventive and social medicine. 19th ed. Jabalpur (India). Banarasidas Bhanot; 2007;327-32.

2. Wild S, Roglic G, Green A, Sicree R, King H. Global prevalence of diabetes. Diabetes Care 2004; 27:1047-53.

3. Arauz-Pacheco C, Parrott MA, Raskin P. Treatment of hypertension in adults with diabetes. Diabetes Care 2003;26(Suppl 1):S80-S82.

4. American diabetes association; clinical practice recommendations 2007. Diabetes Care 2007;30:S4.

5. Ahmad M, et al. Antidiabetic and Hypolipidemic Effects of Aqueous Methanolic Extract of Acacia Nilotica Pods in Alloxan-Induced Diabetic Rabbits. Scand J Lab Anim Sci 2008;35:29-34.

6. Wadood N, Wadood A, Shah SA. Effect of Tinospora cordifolia on blood glucose and total lipid levels of normal and alloxan-diabetic rabbits. Planta Med. 1992;58:131-6.

7. Naglaa ZH, Hesham AM, Hosny Abdel Fadil, Abdel Motal SM. Impact of Metformin on Immunity and Male Fertility in Rabbits with Alloxan-induced Diabetes. Journal of American Science. 2010;6(11):417-26.

8. Stanley P, Prince M, Menon VP. Hypoglycemic and hypolipidaemic action of alcohol extract of Tinospora cordifolia roots in chemical induced diabetes in rats. Phytother Res. 2003;17:410-13.

9. Grover JK, Vats V, Rathi SS. Anti-hyperglycemic effect of Eugenia jambolana and Tinospora cordifolia in experimental diabetes and their effects on key metabolic enzymes involved in carbohydrate metabolism. J Ethnopharmacol. 2000;73(3):461-70.

doi:10.5455/2319-2003.ijbcp20131009

Cite this article as: Tamboli SB, Sontakke SP, Parsode RB. Study of hypoglycemic activity of Tinospora cordifolia in alloxan induced diabetic rabbits. Int J Basic Clin Pharmacol 2013;2:559-61. 